\title{
ECOG Performance Status
}

National Cancer Institute

\section{Source}

National Cancer Institute. ECOG Performance Status. NCI Thesaurus. Code C105721.

A performance status scale designed to assess disease progression and its affect on the daily living abilities of the patient. 